\title{
E Isomer
}

National Cancer Institute

\section{Source}

National Cancer Institute. Elsomer. NCI Thesaurus. Code C92193.

A double bond with its highest priority side groups on opposite sides. 